\author{
Review Article \\ www.ijrap.net (ISSN:2229-3566)
}

\title{
EFFECT OF YOGA ON STRESS: A REVIEW
}

Navedita Kumari ${ }^{1 *}$, Anupam Pathak ${ }^{2}$

${ }^{1}$ PG Scholar, Department of Swasthavritta \& Yoga, Sri Ganganagar College of Ayurvedic Science and Hospital, Tanta University, Sri Ganganagar, India

${ }^{2}$ Professor \& H.O.D., Department of Swasthavritta \& Yoga, Sri Ganganagar College of Ayurvedic Science and Hospital, Tanta University, Sri Ganganagar, India

Received on: 23/06/21 Accepted on: 11/09/21

\begin{abstract}
*Corresponding author
E-mail: drniveditaheer@gmail.com
\end{abstract}

DOI: $10.7897 / 2277-4343.1205152$

\begin{abstract}
Modern life is full of hassles, deadlines, frustrations and demands. For many people, stress is so commonplace that it has become a way of life. Stress is not always bad; stress is a natural human response to the press when faced with challenging and sometimes dangerous situations. Stress is your body's response to changes in your life. Because life involves constant change ranging from every day, routine changes like commuting from home to work to adapt to major life changes like marriage, divorce, or death of a loved one-there is no avoiding stress. It is a subjective and unpleasant feeling of distress. Every one of us irrespective of our age, sex, education, occupation, socioeconomic status, whether living in rural or urban areas face stress. Yoga is an ancient science, which originated in India and many studies have found that yoga and pranayama can be practised to manage and combat stress. Yoga is a form of exercise which is about 5000 years old and originated in India. The word yoga is derived from "Yuj" which means union or joining. It is a dynamic expression of life in terms of how joyful, loving and enthusiastic you are.
\end{abstract}

Keywords: Stress, occupational stress, yoga, pranayama.

\section{INTRODUCTION}

Day by day the technology dependence is increasing in human beings. One of the biggest problems of today's world is tension. Today there are a lot of medicines within easy reach for relieving this tension, however, the effect of these medicines is very limited. Along with tension the quantity of medicines keeps increasing so also do the medicines for a night sound sleep - this cycle keeps on going endlessly. However, if we can unearth the roots of this tension and realize why and where this tension emanates and prepare ourselves to that extent where tension never builds up and if it does it easily soothes down. So do we want a solution to this problem? Do we want to live a peaceful life? If yes, then yoga can help us. Yoga helps to join the individual self with the universal self. Yoga is necessary for the all-around fitness of people now a day.

The term "stress", as it is currently used was coined by Hans Selye in 1936, who defined it as "the non-specific response of the body to any demand for change". Physical or biological stress is an organism's response to a stressor such as an environmental condition or a stimulus. ${ }^{1}$ The body's autonomic nervous system controls your heart rate, breathing, vision changes and more. Its built-in stress response, the "fight-or-flight response," helps the body face stressful situations. When a person has long-term (chronic) stress, continued activation of the stress response causes wear and tear on the body. Physical, emotional and behavioural symptoms develop. In humans, stress typically describes as a negative condition or a positive condition that can have an impact on a person's mental and physical wellbeing.

\section{Types of stress ${ }^{2}$}

1. Acute stress: The most common form of stress is short term and stems from the demands and pressure of the recent past and anticipated demands and pressure of the near future.

2. Alarm stage: The alarm stage is also known as the fight or flight response. During the alarm stage, your brain sends an emergency signal to other parts of your body, which lets those parts know that you're in a dangerous situation. As your body mobilizes itself to react, you can choose between a fight or flight response. The fear, excitement or pressure is evident on the sufferer's face.

3. Exhaustion stage: If a student is preparing for his exams and despite every possible effort, he is not able to relate to his studies, he is bound to get stressed. The stress could reach a height where he/she may feel completely exhausted and helpless to the extent of committing suicide. This is the exhaustion stage.

\section{Symptoms of stress ${ }^{3}$}

Cognitive symptoms

1.Memory problems

2.Poor judgement

3. Constant worrying

4. Seeing only the negative

Emotional symptoms

1.Irritability of short tamper

2.Depression or general unhappiness

3.Feeling overwhelmed 
Behavioral symptoms

1.Eating more or less

2.Isolating yourself from others

3.Nervous habits (eg. Nail biting)

Role of Yoga: Yoga is a philosophical system for personal development that originated in India, over 3000 years ago. The word yoga is derived from the Sanskrit root "yuj" or yujirdhatu word meaning to bind, join, attach to direct and concentrate one's attention on, to use and apply. Yoga is very important for the body. It develops strength and flexibility. Its poses encourage focus and concentration. As a great yoga master, yoga is a methodical effort toward self-perfection through developing your talent potential on the physical, vital, mental, intellectual, and spiritual levels. And the most fundamental step you can take toward expanding the limits of your consciousness is to gain mastery over your mind. ${ }^{4}$ Therefore, yoga is an extraordinary spiritual science of self-development and self-realization that shows us how to develop our full potential in our many-sided lives. It was first devised by the rishis and sages of ancient India and has been maintained by a stream of living teachers ever since, who have continually adapted this science to every generation. Hence, yoga helps in almost every field of our life strengthening one's body, mind and inner self which leads to peaceful life by gaining more health, happiness and inner peace.

Some of the physical benefits of yoga practice include

- Better health

- Decrease of physical tension

- Improved circulation and digestion

- Improved posture

- Normalization of weight

Some of the psychological benefits include

- Calmness

- Improved balance

- Decreased anxiety, hostility and depression

- Improved memory

- Improved mood and sense of well being

\section{Effect of yoga on stress}

Yoga is an ancient science, which originated in India and many studies have found that yoga and pranayama can be practiced combatting stress. Pranayama involves the manipulation of the breath that is the dynamic bridge between the body and mind. Yoga is an ancient art that is defined as the union of the soul with God. Originally, the goal of yoga was called Samadhi or selfrealization. Patanjali is the father of yoga around the sixth century $\mathrm{BC}$ appeared in the massive epic. The Mahabharata was written by sage $\mathrm{V}$. yasa and containing the Bhagavad Gita.

Patanjali introduced- Ashtanga or power yoga- a more demanding workout where you constantly move from one posture to another "flow". The dimensions of yoga are 5

- Pranayama (breathing)

- Asana (postures)

- Yama (restraint)

- Niyama (healthy observances)

- Pratyahara (sensory withdrawal)

- Dharana (concentration)

- Dhyana (meditation)

- Samadhi (higher consciousness)

\section{Types of asanas (postures)}

Vajrasana $^{6}$ : The name comes from the Sanskrit words vajra, a weapon whose name means "thunderbolt" or "diamond. It is the best asana of stress and tension and anxiety it makes the body exceptionally strong and healthy. Vajrayana stimulates the vajra nadi which facilitates good digestion. It helps relieve sciatica, nerve issues and indigestion. "When you sit in vajrasana you obstruct blood flow to the lower part of your body - thighs and legs. This increases blood flow to your pelvic area and stomach due to which bowel movement and digestion becomes better.

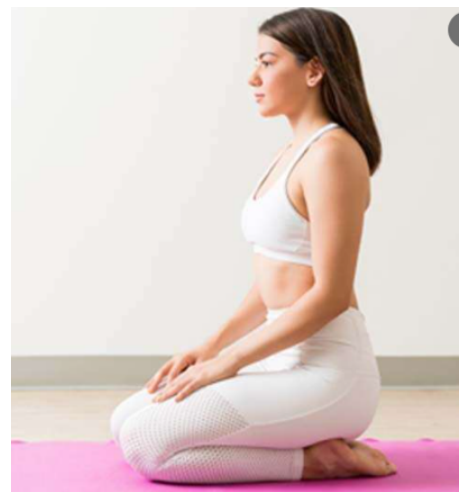

Bhujangasana $^{7}$ (The cobra pose): The pose starts from a downward-facing position with hands flat on the floor below the shoulders. The spine is lengthened, and the buttocks firmed as the head and chest is slowly lifted. The elbow stays close to the body and the eyes lookup. The neck is kept natural.

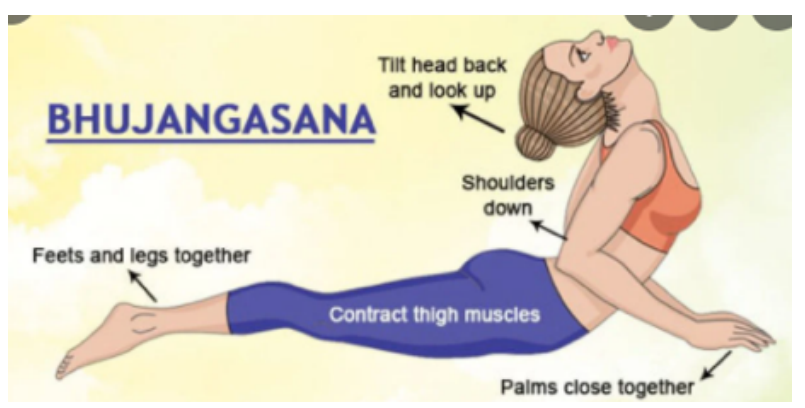

Padamasana $^{\mathbf{8}}$ : Sit on the ground by spreading the legs forward, place the right foot on the left thigh and the left foot on the right thigh. Place the hands on the knee joint, keep the body, back and head erect. Eyes should be closed.

\section{Benefits of yoga}

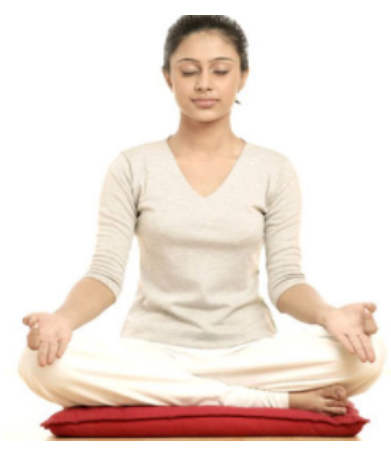

- Mental calmness

- Stress reduction

- Body awareness 


\section{CONCLUSION}

Practicing yoga regularly will rejuvenate our body, mind and inner self. We feel relaxed, energetic, and calm with full positivity. We feel that spirituality and divinity are everywhere. With the help of yoga, one can search that inner and immortal happiness that leads to a peaceful life. So, in conclusion yoga can be a great remedy for stress and can offer some stress relief.

\section{REFERENCES}

1. Banarasidass Bhanot, K. Park, Preventive and social medicine, $24^{\text {th }}$ edition 1167 , Prem Nagar, Nagpur Road, Jabalpur, 482001 (M.P.), India

2. Occupational stress: Introduction in Wikipedia [cited 2021, June 24] Available from: https://en.wikipedia.org/wiki/ Occupational_stress
3. Jarlnto, K., Understanding stress: Comparing between U.S, Japanese and Thai Management styles.

4. Stress \& Stress Management, Clinic Community Health centre, January 2010.

5. Dr. Suresh Chandra Shrivastava, Patanjalayogasutra, Chaukhamba Surbharti Prakashan, Varanasi, U.P. India. 2/29

6. Swami Niranjanananda Saraswati, Gheranda Samhita, Yoga publication trust, Munger, Bihar, India. 2/13, p. 185

7. Swami Niranjanananda Saraswati, Gheranda Samhita, Yoga publication trust, Munger, Bihar, India. 2/42,43 p. 251

8. Swami Niranjanananda Saraswati, Gheranda Samhita, Yoga publication trust, Munger, Bihar, India. 2/9, p. 174

\section{Cite this article as:}

Navedita Kumari and Anupam Pathak. Effect of yoga on stress: A Review. Int. J. Res. Ayurveda Pharm. 2021;12(5):90-92 http://dx.doi.org/10.7897/2277-4343.1205152

Disclaimer: IJRAP is solely owned by Moksha Publishing House - A non-profit publishing house, dedicated to publishing quality research, while every effort has been taken to verify the accuracy of the content published in our Journal. IJRAP cannot accept any responsibility or liability for the site content and articles published. The views expressed in articles by our contributing authors are not necessarily those of IJRAP editor or editorial board members. 